\title{
microRNA target prediction programs predict many false positives
}

\author{
Natalia Pinzón, ${ }^{1}$ Blaise Li, ${ }^{1}$ Laura Martinez, ${ }^{1}$ Anna Sergeeva, ${ }^{1,5}$ Jessy Presumey, ${ }^{2,3,6}$ \\ Florence Apparailly, 2,3,4 and Hervé Seitz ${ }^{1}$ \\ ${ }^{1}$ Institut de Génétique Humaine, CNRS UPR 1142, 34396 Montpellier, France; ${ }^{2}$ INSERM, U1183, IRMB, University Hospital St Éloi, \\ 34295 Montpellier, France; ${ }^{3}$ University of Medicine, 34060 Montpellier, France; ${ }^{4}$ Clinical Department for Osteoarticular Diseases, \\ University Hospital Lapeyronie, 34295 Montpellier, France
}

\begin{abstract}
According to the current view, each microRNA regulates hundreds of genes. Computational tools aim at identifying microRNA targets, usually selecting evolutionarily conserved microRNA binding sites. While the false positive rates have been evaluated for some prediction programs, that information is rarely put forward in studies making use of their predictions. Here, we provide evidence that such predictions are often biologically irrelevant. Focusing on miR-223-guided repression, we observed that it is often smaller than inter-individual variability in gene expression among wild-type mice, suggesting that most predicted targets are functionally insensitive to that microRNA. Furthermore, we found that human haplo-insufficient genes tend to bear the most highly conserved microRNA binding sites. It thus appears that biological functionality of microRNA binding sites depends on the dose-sensitivity of their host gene and that, conversely, it is unlikely that every predicted microRNA target is dose-sensitive enough to be functionally regulated by microRNAs. We also observed that some mRNAs can efficiently titrate microRNAs, providing a reason for microRNA binding site conservation for inefficiently repressed targets. Finally, many conserved microRNA binding sites are conserved in a microRNAindependent fashion: Sequence elements may be conserved for other reasons, while being fortuitously complementary to microRNAs. Collectively, our data suggest that the role of microRNAs in normal and pathological conditions has been overestimated due to the frequent overlooking of false positive rates.
\end{abstract}

[Supplemental material is available for this article.]

Together with a protein member of the Argonaute family, microRNAs (miRNAs) constitute the RNA-induced silencing complex (RISC), which represses specific mRNA targets by translation inhibition and mRNA decay (Iwakawa and Tomari 2015). Target recognition is typically mediated by imperfect base-pairing between the miRNA and the mRNA. The large number of known miRNAs (several hundred distinct miRNAs in most animal model organisms) (Kozomara and Griffiths-Jones 2014), as well as the poorly specific rules for target recognition, result in a large fraction of coding genes predicted to be repressed by miRNAs in animals (between 19,000 and 20,000 human genes according to Betel et al. 2010 and Paraskevopoulou et al. 2013). Indeed, even after accounting for the background of false-positive predictions, about 11,000 human genes are predicted to be conserved targets of miRNAs (Friedman et al. 2009). Not surprisingly then, miRNAs have been proposed to control numerous biological processes in healthy conditions or in diseases (Bartel 2009; Shenoy and Blelloch 2014; Hata and Lieberman 2015).

From a quantitative point of view, however, miRNA target repression appears to be very limited, with endogenous miRNAs repressing their targets less than twofold, according to highthroughput proteomic and transcriptomic experiments (Baek et al. 2008; Selbach et al. 2008). Hence, it is currently believed that miRNAs exert most of their biological functions by fine-tun-

Present addresses: ${ }^{5} \mathrm{MSU}$, The Museum of Natural History, Moscow, Russia, 119991; ${ }^{6}$ Children's Hospital, Boston, MA 02115, USA Corresponding author: herve.seitz@igh.cnrs.fr

Article published online before print. Article, supplemental material, and publication date are at http://www.genome.org/cgi/doi/10.1101/gr.205146.116. ing many mRNA targets, precisely setting their protein output to its optimal abundance (Bartel and Chen 2004).

Yet, it is well-established that the activity of most genes in animals is robust to such small changes in gene expression levels, yielding constant phenotypes despite variable expression. Gene expression typically fluctuates by twofold when comparing two individuals in the human population (Cheung et al. 2003), two pools of individuals from a genetically homogenized Drosophila population (Laurie-Ahlberg et al. 1982), or two phenotypically identical mouse neural stem cells (Subkhankulova et al. 2008). Natural polymorphism in cis-regulatory sequences in the human population causes a large variability in gene expression, which is often greater than twofold (Rockman and Wray 2002).

Neutral regulatory events should be excluded from predictions. Therefore, comparative genomics is commonly used to identify miRNA binding sites that have been phylogenetically conserved. Assuming that conservation is due to a selective pressure, significant conservation of a miRNA binding site is perceived as an indication of physiological functionality (Bartel 2009). Several miRNA target prediction programs have been written, most of which select candidate binding sites by scoring their phylogenetic conservation (Friedman and Burge 2014). It seems that most effective miRNA binding sites in animals contain a perfect match to the "seed" (nucleotides 2-7) of the miRNA (Lai 2002; Lewis et al. 2003; Krek et al. 2005): Prediction programs typically

(C) 2017 Pinzón et al. This article is distributed exclusively by Cold Spring Harbor Laboratory Press for the first six months after the full-issue publication date (see http://genome.cshlp.org/site/misc/terms.xhtml). After six months, it is available under a Creative Commons License (Attribution-NonCommercial 4.0 International), as described at http://creativecommons.org/licenses/ by-nc/4.0/. 
select conserved perfect or almost perfect seed matches in mRNA sequences, further refining candidate lists with various sequence or structure criteria. These computational programs are heavily used by the community in addition to experimental assessment of target repression: Phylogenetic conservation is taken as a proof that an experimentally measured repression plays a physiological role. Estimates of the false positive rate for conserved sites of some programs have been published, and they are close to 50\% (Krek et al. 2005; Lewis et al. 2005; Friedman et al. 2009), yet this information is frequently ignored in published studies making use of these programs. We thus decided to explore the sources of false positives in miRNA target prediction.

\section{Results}

\section{Sensitivity of gene activity to miRNA}

The transcriptome-wide effect of a miRNA in a primary cell type has been measured in a few experimental setups, including target repression by granulocyte lineage-specific miR-223 in mouse neutrophils (Chen et al. 2004; Baek et al. 2008; Johnnidis et al. 2008). The amplitude of miR-223-mediated repression on its targets was measured by comparing mRNA and protein levels in wild-type and Mir223 mutant neutrophils (but note that the experimental procedure did not allow the measurement of inter-individual variability: cells were pooled from several individual mice, thus, averaging out potential inter-individual differences) (Baek et al. 2008).

We reasoned that inter-individual variability in gene expression among wild-type animals is a faithful estimation of the robustness of gene activity relative to fluctuations in gene expression levels. Wild-type populations, shaped by thousands of years of evolution, have been depleted in genome variants that lead to detrimental gene expression levels. If miRNA binding sites had been selected because targeting by miRNAs maintains gene expression at a nondetrimental level, purifying selection should have eliminated any regulatory element that mediates variation in gene expression with amplitudes similar or higher to miRNA-guided repression. We thus measured variability in neutrophil gene expression among wild-type mice.

We isolated neutrophils from five wild-type mice (see Supplemental Table S1 for neutrophil purity) and quantified mRNA abundance by whole-genome arrays. The effect of miRNAs on the abundance of target mRNAs is a good approximation of the effect of the miRNA on protein abundance, at least at steady-state in vertebrates (Hendrickson et al. 2009; Guo et al. 2010; Bazzini et al. 2012), and transcriptomic methods are more sensitive than proteomic methods (Baek et al. 2008; Selbach et al. 2008). Measuring pure translational repression by miRNAs would thus marginally improve the accuracy of our analysis, but it is currently not feasible at a genome-wide scale. In order to ensure that the dynamic range in our experiment is the same as in the experiment described by Baek et al. (2008), we used the same transcriptomic technology (Affymetrix whole-genome arrays), using 3-month-old C57BL/6 males as in that study.

In order to measure the technical noise introduced by the experimental procedure, we also performed the same experiment on the pooled blood of five additional mice (see Fig. 1A). Taking into account technical variability, we could then compare the amplitude of inter-individual variation to the repressive effect of miR223 on each predicted target (see Fig. 1B for an example). Each of the 10 mice was pathogen-free (39 common pathogens were screened), ensuring that their immune state was as homogeneous as possible. miR-223 targets were predicted using TargetScan mouse (v. 6.2), which appears to be the most reliable predictor (Agarwal et al. 2015): 196 conserved targets are predicted, 192 of which are probed by the whole-genome array. Individual-to-individual variability in gene expression is typically twofold when comparing the most highly expressing mouse to the least highly expressing mouse among the five tested mice (see Supplemental Fig. S1). Our analysis shows that, for 150 predicted targets out of 192, inter-individual variability in gene expression exceeds the median effect of miR-223 on these genes (see Fig. 1C). Employing another normalization method for microarray data (Loess instead of RMA) only strengthened this result: Even with a $p$-value cutoff of 0.01 , inter-individual variability exceeded the miR-223 effect for 186 genes out of 192.

Real targets for miR-223 (i.e., genes whose repression by the miRNA triggers a macroscopic phenotype) should exhibit tightly regulated expression levels among wild-type mice. Hence, we expect real targets to be enriched among the 42 genes whose inter-individual variability does not appear to exceed miR-223-guided repression. We note that one of these genes, Nlrp3 (see Fig. 1D), could be responsible for the neutrophil hyperactivity phenotype of Mir223 mutants (Johnnidis et al. 2008; Bauernfeind et al. 2012; Haneklaus et al. 2012). Restricting our analysis to mRNA/miRNA interactions with some experimental support (Vlachos et al. 2015) increased slightly, but not significantly, the proportion of genes with low inter-individual variability (see Supplemental Table S2).

Our experiment only probed gene expression levels in mature neutrophils, whereas miR-223 is also expressed in neutrophil progenitors (Johnnidis et al. 2008). Some evidence suggests that misregulation of one predicted target, $\mathrm{Mef2c}$, is responsible for the high neutrophil titer phenotype of Mir223 mutants, while it is not responsible for the hyperactivity phenotype (Johnnidis et al. 2008). We note that $M e f 2 c$ expression levels appear highly variable in mature neutrophils, and that gene does not belong to the list of 42 genes enriched for real targets. These observations could mean that the two reported phenotypes for Mir223 mutant mice are genetically separable. For example, the hyperneutrophilic phenotype could be due to the misregulation of $M e f 2 c$ in progenitor cells, while the hyperactivity phenotype could be due to the misregulation of some of these 42 genes in mature neutrophils.

It could be argued that the activity of miR-223 in neutrophils is not uniform among the five tested mice, and the mouse expressing targets most abundantly may also express the highest level of miR-223, eventually bringing target translation to the same level as in the other mice. This hypothesis would imply that, for every target, the five mice would appear in the same order if ranked by target abundance. This is not the case: There is no global trend suggesting that miR-223 targets are coordinately up- or down-regulated from one individual mouse to the next (Supplemental Fig. S2).

Hence, most predicted targets for miR-223 in neutrophils may not be functionally affected by the miRNA: The effect of miR-223 on these genes is smaller than inter-individual fluctuations in gene expression among wild-type mice. Yet, our experiment certainly underestimated inter-individual variability: First, the range of gene expression levels could only increase if more than five mice were analyzed. Second, we analyzed mice from an inbred strain (the C57BL/6 strain), which are more genetically homogeneous than wild mice. Therefore, the proportion of miR-223-insensitive predicted targets in neutrophils is probably even larger than 150/ 192.

In this experiment, we analyzed a single miRNA (miR-223) in a single cell type (mature neutrophils). Further analyses on 

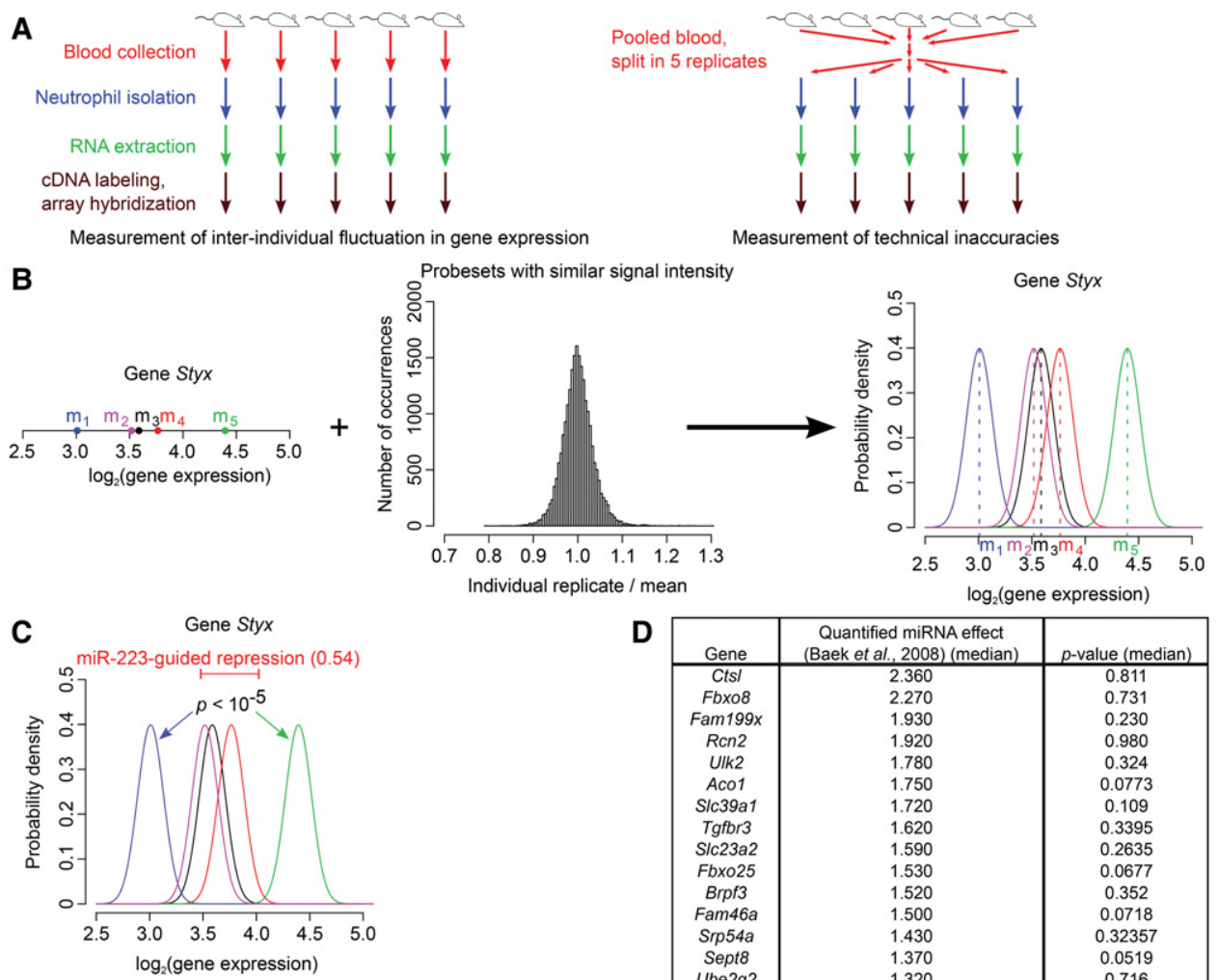

\begin{tabular}{|c|c|c|}
\hline Gene & $\begin{array}{l}\text { Quantified miRNA effect } \\
\text { (Baek et al., 2008) (median) }\end{array}$ & $p$-value (median) \\
\hline Ctsl & 2.360 & 0.811 \\
\hline Fbxo8 & 2.270 & 0.731 \\
\hline Fam199x & 1.930 & 0.230 \\
\hline Ren2 & 1.920 & 0.980 \\
\hline Ulk2 & 1.780 & 0.324 \\
\hline Aco1 & 1.750 & 0.0773 \\
\hline Slc39a1 & 1.720 & 0.109 \\
\hline Tgfbr3 & 1.620 & 0.3395 \\
\hline SIc23a2 & 1.590 & 0.2635 \\
\hline $\mathrm{Fbxo25}$ & 1.530 & 0.0677 \\
\hline Brpf3 & 1.520 & 0.352 \\
\hline Fam46a & 1.500 & 0.0718 \\
\hline Srp54a & 1.430 & 0.32357 \\
\hline Sept8 & 1.370 & 0.0519 \\
\hline Ube2q2 & 1.320 & 0.716 \\
\hline Frmd4a & 1.280 & 0.0933 \\
\hline Srp54b & 1.280 & 0.543 \\
\hline Arfip1 & 1.270 & 0.342 \\
\hline Orc4 & 1.270 & 0.2185 \\
\hline Rasa1 & 1.250 & 0.0646 \\
\hline Nlrp3 & 1.240 & 0.432 \\
\hline Mospd1 & 1.220 & 0.0739 \\
\hline Srsf12 & 1.220 & 0.097545 \\
\hline Acvr2a & 1.150 & 0.06824 \\
\hline Scn1a & 1.110 & 0.102 \\
\hline Tet3 & 1.100 & 0.217 \\
\hline Smarcd1 & 1.090 & 0.05105 \\
\hline$R c 3 h 1$ & 1.070 & 0.0734 \\
\hline Fgfr2 & 1.040 & 0.06945 \\
\hline Tmprss11e & 0.981 & 0.0502 \\
\hline Gpr22 & 0.960 & 0.050285 \\
\hline Zcchc14 & 0.943 & 0.0894 \\
\hline Sh $3 p \times d 2 b$ & 0.918 & 0.128 \\
\hline Slc35f1 & 0.917 & 0.4385 \\
\hline Plce1 & 0.911 & 0.254 \\
\hline Anks $1 b$ & 0.899 & 0.0694 \\
\hline Lelp1 & 0.889 & 0.0766 \\
\hline Arpp19 & 0.873 & 0.245 \\
\hline Tmem170 & 0.870 & 0.127 \\
\hline$C b \times 5$ & 0.777 & 0.07605 \\
\hline Pik3c2a & 0.541 & 0.7465 \\
\hline$Z x d c$ & 0.458 & 0.745 \\
\hline
\end{tabular}

Figure 1. Inter-individual variability in miR-223 target expression is frequently larger than miR-223-guided repression. (A) Principle of the experiment. $(B)$ The measured microarray signal is the sum of the underlying biological value and technical noise (here illustrated with the Styx gene). Measured signals $\left(m_{1}-m_{5}\right)$ are deconvoluted using the measured technical variability (see Supplemental Experimental Procedures). (C) For each predicted miR-223 target, the amplitude of miR-223-guided repression is compared to the amplitude of gene expression variability across the five mice (here illustrated with the Styx gene). The $p$-value measures the probability that the underlying biological variability is smaller than miRNA-guided repression. We used the median repression value measured by Baek et al. (2008) (represented by the red horizontal bar) to estimate miR-223-guided repression. (D) Genes whose inter-individual fluctuations are not significantly larger than miR-223-guided repression $(p \geq 0.05)$. Middle column: fold-change due to miR-223-mediated repression according to data of Baek et al. (2008) (note that some genes have a fold-change $<1$, thus appearing to be up-regulated by the miRNA: these genes may be indirectly affected by miR-223). Right column: $p$-value, measured as in panel $C$ (median across all probe sets for that gene).

additional miRNAs would be required to assess experimentally the generality of our conclusions. Among the broadly conserved miRNAs, miR-223 is reported to have an unusually high proportion of false-positive predictions, with only 40 of its 196 conserved targets listed as having a "probability of conserved targeting" $\left(P_{C T}\right)$ exceeding 50\% (Friedman et al. 2009). We also wish to point out that constitutive deletion of the miRNA gene may have resulted in compensatory gene expression changes in Mir223 mutant neutrophils, potentially blurring the direct effects of a loss of miR-223. With these limitations in mind, our data suggest that most individual miR-223 binding sites are unlikely to play a biologically relevant role in repressing target genes in neutrophils.

We also have to emphasize that an alternative interpretation can be proposed: It can be envisioned that some variably expressed

\section{Genome Research}

www.genome.org 
genes trigger detrimental phenotypes if expressed above a given threshold. miRNA-mediated repression would thus only be beneficial in individuals (or in cells) at the high end of the expression range. In that case, target repression would be conserved because of its utility in the population at large, without being required in every individual. If this were the case, and given the large number of variably expressed genes in our data, such "fail-safe" interactions (Bartel 2009) would thus outnumber fine-tuning interactions in neutrophils.

\section{Dose-sensitive genes bear the most highly conserved miRNA binding sites}

In order to test the generality of our conclusion regarding the frequent insensitivity to miRNAs, we explored the relationship between dose-sensitivity and gene targeting by miRNAs. Real targets are expected to bear the most highly conserved miRNA binding sites. Genes whose repression by the miRNA is physiologically inconsequential should lose their miRNA binding sites more easily in evolution, even if the mRNA/miRNA interaction plays a miRNA-titrating function (Seitz 2009). Hence, the existence of false positives in miRNA target prediction implies that the most dosesensitive genes should exhibit the most highly conserved miRNA binding sites.

In contrast, considering that predicted miRNA targets are devoid of false positives would simply assume that every predicted target gene is dose-sensitive enough to be functionally affected by miRNAs. miRNA binding site conservation is not expected to correlate with dose-sensitivity: Conservation should depend on the functional importance of the repression of any given gene but not on its dose-sensitivity, which is always assumed to be sufficient for functional regulation.

Probably the most accurate available metrics for miRNA binding site conservation is the $P_{C T}$ described by Friedman et al. (2009). It takes into account the topology of the phylogenetic tree as well as differences in overall conservation between untranslated regions (UTRs) to estimate the likelihood that a seed match is under selective pressure.

There exists currently no highthroughput method to identify dosesensitive genes in metazoans. A curated list of haplo-insufficient genes (a type of dose-sensitive genes) is, however, available in humans (Dang et al. 2008). miRNA binding site conservation is significantly higher in haplo-insufficient genes than in other human genes (see Fig. 2A). Computational methods have also been proposed to predict dose-sensitive genes: Huang et al. (2010) published a heuristic method based on genomic, molecular, and functional properties of known human haplo-insufficient genes. For each gene, we thus compared its probability of haploinsufficiency (from the Huang et al. 2010 data) to its highest $P_{C T}$ (i.e., across all miRNA families with predicted binding sites in that gene, we extracted that with the highest $\left.P_{C T}\right)$. We found that the probability of being haplo-insufficient correlates positively with the conservation of the most conserved miRNA binding site (see Fig. 2B).

Such correlation would not have been expected if every computationally predicted target was biologically sensitive to miRNA action. The fact that miRNA binding site conservation seems to depend on the host gene's dose sensitivity rather suggests that every predicted target is actually not dose-sensitive enough to be functionally affected by miRNAs. Our results thus confirm that miRNA target predictions are contaminated with large numbers of false positives, which were estimated to constitute about half of current prediction lists for some programs (Krek et al. 2005; Friedman et al. 2009).

\section{Assessement of miRNA titration by mRNAs}

If, indeed, a large fraction of predicted miRNA targets are functionally insensitive to the modest miRNA-guided repression, one may ask why they bear phylogenetically conserved seed matches. We proposed that some miRNA binding sites may serve as miRNA titrators: Some sites may be conserved because of their miRNA modulating activity, not because of their weak repression of the mRNA (Seitz 2009).

Others have tentatively probed the miRNA-titrating activity of an mRNA (competing endogenous RNA, "ceRNA") (Poliseno et al. 2010; Salmena et al. 2011), but the proposed titrator is not abundant enough to modulate miRNA activity (Ebert and Sharp 2010). Published experimental evidence relies essentially on ceRNA overexpression experiments, which do not address the titrating activity of ceRNA endogenous levels, and ceRNA knockdown experiments by RNAi, where overaccumulation of miRNA targets was perceived as a proof of ceRNA activity. However, the siRNAs used in these experiments exhibit off-target seed matches on target sequences, providing an alternative explanation of the
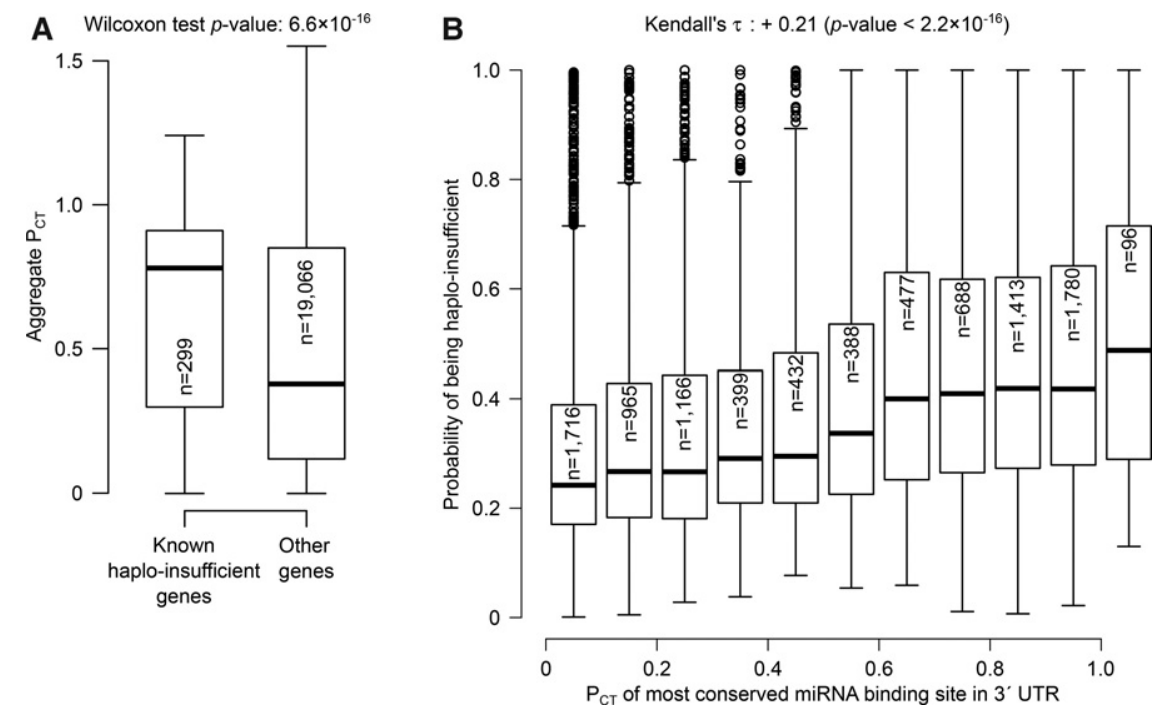

Figure 2. Human haplo-insufficient genes tend to bear the most highly conserved miRNA binding sites. (A) Known haplo-insufficient genes in humans (Dang et al. 2008) exhibit more conserved miRNA binding sites than other human genes. $(B)$ Conservation of miRNA binding sites correlates with the probability of human genes for being haplo-insufficient, as calculated by Huang et al. (2010) (genes were binned into boxplots according to their $P_{C T}$ for clarity). In every boxplot in this figure, the number of genes in each category is indicated inside the boxes. Note: Even though the $P_{C T}$ was initially defined as a probability (Friedman et al. 2009), values in the latest $P_{C T}$ data set (in TargetScan v7, described in Agarwal et al. [2015]) can be larger than 1. 

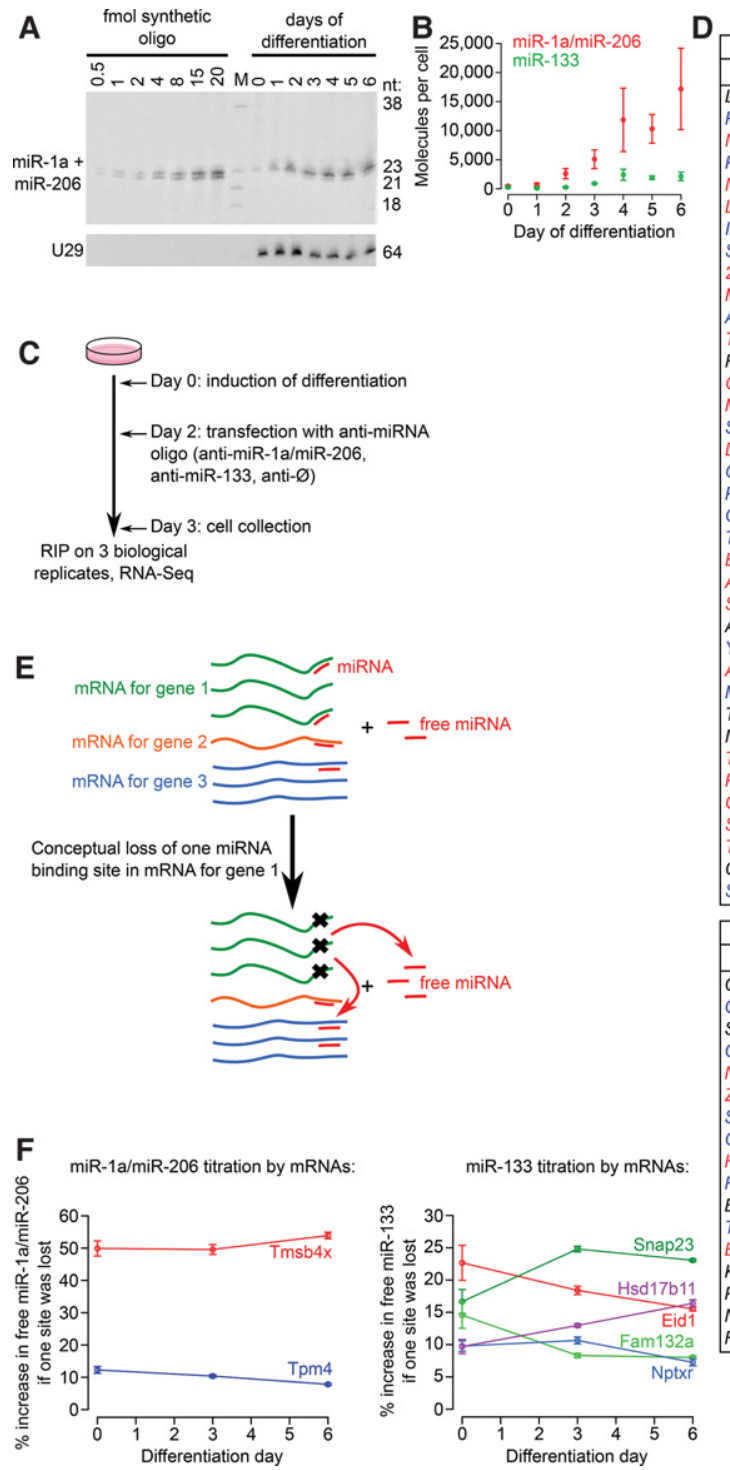

\begin{tabular}{|l|c|c|}
\hline \multicolumn{3}{|c|}{ miR-1a/miR-206 inhibition experiment } \\
\hline \multicolumn{1}{|c|}{ mRNA } & log $_{2}$ (fold-change) & Adjusted p-value \\
\hline L3hypdh & -5.330 & $4.57 \mathrm{e}-02$ \\
Pla2g4c & -5.180 & $3.18 \mathrm{e}-02$ \\
Nrk & -3.770 & $1.86 \mathrm{e}-02$ \\
Park2 & -2.870 & $1.23 \mathrm{e}-02$ \\
Nim1k & -2.690 & $3.53 \mathrm{e}-02$ \\
Lyplal1 & -2.600 & $4.03 \mathrm{e}-09$ \\
Inca1 & -2.540 & $4.57 \mathrm{e}-02$ \\
Sfrp4 & -2.330 & $8.39 \mathrm{e}-03$ \\
2210408/21Rik & -2.140 & $7.70 \mathrm{e}-07$ \\
Mlph & -2.030 & $8.12 \mathrm{e}-03$ \\
A430078G23Rik & -2.020 & $1.28 \mathrm{e}-02$ \\
Tmsb4x & -2.010 & $1.93 \mathrm{e}-21$ \\
Rpl39 & -1.840 & $1.49 \mathrm{e}-15$ \\
Gbp8 & -1.780 & $1.86 \mathrm{e}-02$ \\
Mab21/3 & -1.770 & $3.60 \mathrm{e}-02$ \\
Sv2b & -1.710 & $1.23 \mathrm{e}-02$ \\
Dynlt1a & -1.590 & $4.83 \mathrm{e}-02$ \\
Gpr39 & -1.550 & $3.22 \mathrm{e}-02$ \\
Prkag2 & -1.480 & $2.50 \mathrm{e}-02$ \\
Osbpl10 & -1.450 & $2.50 \mathrm{e}-02$ \\
Tesk2 & -1.330 & $8.39 \mathrm{e}-03$ \\
Elof1 & -1.330 & $8.64 \mathrm{e}-06$ \\
Arrdc2 & -1.280 & $4.08 \mathrm{e}-02$ \\
Serpine2 & -1.150 & $2.50 \mathrm{e}-02$ \\
Atp1a1 & -1.130 & $3.78 \mathrm{e}-06$ \\
Yif1b & -1.110 & $2.75 \mathrm{e}-04$ \\
Ascc1 & -1.030 & $2.36 \mathrm{e}-02$ \\
Mtpap & -1.000 & $2.50 \mathrm{e}-02$ \\
Tprn & -0.993 & $1.21 \mathrm{e}-02$ \\
Npri2 & -0.975 & $4.32 \mathrm{e}-02$ \\
Tmem55b & -0.881 & $1.21 \mathrm{e}-02$ \\
Pdpn & -0.879 & $5.72 \mathrm{e}-03$ \\
Cap1 & -0.836 & $8.12 \mathrm{e}-03$ \\
SIc25a17 & -0.815 & $2.50 \mathrm{e}-02$ \\
Tpm4 & -0.798 & $1.23 \mathrm{e}-02$ \\
Cox6a2 & -0.777 & $3.60 \mathrm{e}-02$ \\
Spp1 & -0.762 & $2.00 \mathrm{e}-02$ \\
\hline
\end{tabular}

\begin{tabular}{|l|c|c|}
\hline \multicolumn{3}{|c|}{ miR-133 inhibition experiment } \\
\hline \multicolumn{1}{|c|}{ mRNA } & $\log _{2}$ (fold-change) & Adjusted $p$-value \\
\hline Ccdc65 & -2.680 & $4.45 \mathrm{e}-02$ \\
Ctsc & -2.430 & $8.36 \mathrm{e}-03$ \\
Samd9I & -2.360 & $9.87 \mathrm{e}-03$ \\
Cnksr1 & -2.240 & $2.49 \mathrm{e}-04$ \\
Nptxr & -2.020 & $3.70 \mathrm{e}-04$ \\
Zff563 & -1.800 & $3.70 \mathrm{e}-04$ \\
Snap23 & -1.410 & $8.18 \mathrm{e}-08$ \\
Gsg11 & -1.380 & $2.54 \mathrm{e}-03$ \\
Hsd17b11 & -1.180 & $5.33 \mathrm{e}-03$ \\
Fam132a & -1.180 & $4.45 \mathrm{e}-02$ \\
Btbd17 & -1.150 & $1.05 \mathrm{e}-02$ \\
Tm6sf1 & -1.110 & $2.62 \mathrm{e}-02$ \\
Eid1 & -1.050 & $4.62 \mathrm{e}-02$ \\
Kcnk5 & -1.030 & $8.18 \mathrm{e}-03$ \\
Pgam2 & -0.993 & $3.70 \mathrm{e}-04$ \\
Nmrk2 & -0.881 & $9.87 \mathrm{e}-03$ \\
Rpl7a & -0.796 & $9.57 \mathrm{e}-03$ \\
\hline
\end{tabular}

Figure 3. Identification of candidate miRNA-titrating mRNAs in differentiating $C 2 C 12$ cells. (A) Left lanes: synthetic miR-1a and miR-206 (for calibration). (M) Size marker. Right lanes: $20 \mu g$ total RNA from differentiating $C 2 C 12$ cells. (B) Quantification of three biological replicates of the experiment shown in panel $A$ for each miRNA family (mean \pm standard error). (C) Experimental identification of miR- $1 \mathrm{a} / \mathrm{miR}$ 206 and miR-133 targets in C2C12 cells. Cells were transfected with 2'-O-Me oligonucleotides directed against miR-1 $a$ and miR-206, against miR-133, or against no murine miRNA ("anti- $\varnothing^{\prime \prime}$ ). mRNAs immunoprecipitated with AGO proteins were quantified by poly(A)-independent RNA-seq. (D) Identified miRNA targets for miR-1a/miR-206 (top panel) and miR-133 (bottom panel). Red: mRNAs with 3' UTR perfect seed matches. Blue: mRNAs whose best 3' UTR match is one of the top three enriched imperfect matches (CNATTCC, CATNCC, or CNTTCC for miR-1a/miR-206; GACCANA, GNACCAA, or GACNCAA for miR-133). (E) Free and bound miRNA concentrations were calculated from our measures, and after conceptual loss of the miRNA binding site of interest. $(F)$ Binding sites that exert the highest titrating activity ( $>10 \%$ increase in free miRNA concentration if site is lost). observed decrease in target mRNAs upon ceRNA knock-down. Consequently, the consensus now states that mRNAs are unlikely to exert any noticeable titration of miRNAs in the general case (Garcia et al. 2011; Wee et al. 2012; Denzler et al. 2014). It has been proposed that efficient titration could be restricted to high-affinity target sites, for miRNAs with a low miRNA:target ratio (Bosson et al. 2014). But another study, performed on a similar biological system with a different methodology, concluded that even poorly expressed miRNAs are unlikely to be efficiently titrated by any individual mRNA (Denzler et al. 2016).

In order to compare mRNA and miRNA concentrations in a meaningful manner, the analyzed biological sample has to be as homogeneous as possible. We thus decided to study the murine C2C12 cell line. We focused on two myotube-specific miRNA families: miR-1a/ miR-206 and miR-133. Both are expressed during the differentiation of C2C12 into myotubes (Chen et al. 2006; Kim et al. 2006), which is inducible in culture, and miR-1a/miR-206 is involved in the control of differentiation (Goljanek-Whysall et al. 2012).

Quantifying miR-1a/miR-206 and miR-133 by calibrated Northern blots (see Fig. 3A), we found that the abundance of miR-1a/miR-206 molecules per cell increases from $\approx 500$ (differentiation day 0 ) to $\approx 17,000$ (day 6), while the abundance of miR-133 increases from $\approx 250$ (day 0 ) to $\approx 2400$ (day 4) molecules per cell (see Fig. 3B).

RNA targets for these miRNAs were identified by AGO RIP-seq (RNA immunoprecipitation followed by poly[A]-independent RNA-seq). In order to identify and exclude nonspecific purification of untargeted mRNAs-e.g., miRNA-independent recruitment of RISC on mRNAs (Leung et al. 2011) — we performed differential RIP-seq (similar to the differential CLIP described by Loeb et al. [2012]) between cells transfected with antisense oligonucleotides against miR-1a and miR-206, or against miR-133, and with a control oligonucleotide that does not match any murine miRNA seed sequence (see Fig. 3C; Supplemental Fig. S3). Transfected antisense oligonucleotides can efficiently inhibit miRNAs, in particular in C2C12 cells (Hutvágner et al. 2004; Goljanek-Whysall et al. 2012). Cells were transfected after $2 \mathrm{~d}$ of differentiation, then $1 \mathrm{~d}$ later they were cross-linked and AGO-RNA complexes were immunoprecipitated for RNA-seq library preparation. Each condition was analyzed as three biological replicates.

mRNAs that are reproducibly immunoprecipitated in the three control replicates, while being depleted in the three replicates of antisense oligonucleotide-treated cells, were annotated as "experimentally identified mRNA targets." Our procedure identified 37 targets for the miR-1a/miR-206 family and 17 targets for the miR-133 family (note that these are all coding RNAs, but noncoding RNAs were included in our analysis) (see Fig. 3D). Approximately 40\% of our experimentally identified targets bear perfect seed matches to the miRNA of interest in their 3' UTRs. As previously reported (Loeb

\section{Genome Research}

www.genome.org 
et al. 2012; Agarwal et al. 2015), experimentally identified targets also frequently exhibit imperfect seed matches for the miRNAs of interest (shown in blue in Fig. 3D).

With miRNA target lists in hand, we quantified mRNA abundance by calibrated ultradeep RNA-seq in the three biological replicates of differentiating C2C12 cells at day 0 , day 3, and day 6 (see sequencing statistics in Supplemental Table S3; calibration scatter plots are shown in Supplemental Fig. S4A: calibration precision is within a factor $\approx 2$ ). Unsupervised clustering of the RNA-seq data indicates high replicate-to-replicate reproducibility and reveals a differentiation signature in gene expression patterns (see Supplemental Fig. S4B).

Combining RNA quantification with our measurement of cell volume, we could calculate intracellular RNA concentrations for miRNAs and mRNAs. Using the law of mass action, we used the published dissociation constant between murine RISC and its targets (Wee et al. 2012) to calculate the equilibrium between free and bound miRNA for both miR-1a/miR-206 and miR-133 families. (The dissociation constant between RISC and its targets was measured on let-7-loaded RISC [Wee et al. 2012], but we note that miR-1a/miR-206 and miR-133 seeds have similar predicted affinities to their seed matches, within 15\%.) To calculate total miRNA binding site concentration, we weighted the concentration of every experimentally identified target by its number of seed matches (considering perfect seed matches as well as the three most frequently observed imperfect seed matches). Performing the same calculation after conceptual loss of a single binding site in a single target (i.e., weighting that target's concentration by number of sites -1 instead of number of sites) allowed us to evaluate the individual contribution of each binding site to miRNA titration (see Fig. 3E). This analysis predicts that several miRNA binding sites exert a strong titrating effect on miR-1a/miR-206 or miR-133 (seven mRNAs appear to titrate at least $10 \%$ of either miR-1a/miR-206 or miR-133 in at least one time point) (see Fig. 3F). For instance, Tmsb $4 x$ appears to titrate half of the free pool of miR-1a/miR-206 at each time point: If Tmsb4x lost its miR-1a/miR-206 binding site, the free pool of miR-1a/miR-206 would be expected to rise by $\approx 50 \%$. Of note, the dynamical behavior of these seven strong titrators does not differ significantly from that of the other experimentally identified targets ( $p$-value $=1$ both for miR- $1 \mathrm{a} / \mathrm{miR}-206$ and for miR-133 according to a two-way ANOVA assessing both the contribution of differentiation time and of the titrating status to gene expression dynamics).

In order to verify experimentally the titrating effect of $T m s b 4 x$ on miR-1a/miR-206 availability, we mutated its 3' UTR in C2C12 cells with high-fidelity nuclease "SpCas9-HF1" (Kleinstiver et al. 2016). Using homologous recombination, we introduced a reporter cassette for miR-1a/miR-206 activity, while simultaneously mutating the Tmsb $4 x$ miR-1a/miR-206 seed match (see Fig. 4A). As a control, we also generated cell lines with the same reporter cassette but without any mutation in the Tms $b 4 x$ miR-1a/miR-206 seed match. Nine independent polyclonal cell lines were obtained: five wildtype lines and four lines where the Tmsb4x miR-1a/miR-206 seed match is mutated. In each of the mutant lines, $\sim 50 \%-80 \%$ of Tmsb4x alleles appear to be mutated (see Supplemental Fig. S5). Cells were then differentiated, and miR-1a/miR-206 activity was monitored by quantifying luciferase activity: Mutant cells exhibit a significantly lower reporter activity than wild-type cells, demonstrating that endogenous levels of the Tms $b 4 x$ mRNA indeed strongly titrate miR-1a/miR-206 in C2C12 cells (see Fig. 4B).

Previous analyses indicate that only miRNA families with a low miRNA:target ratio are susceptible to titration (Bosson et al. 2014).

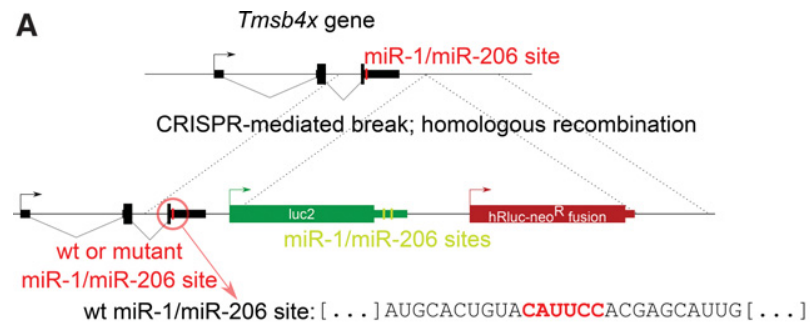

mutant miR-1/miR-206 site: [ . . . ] AUGCACUGUAUCCAUCACGAGCAUUG [ . . . ]

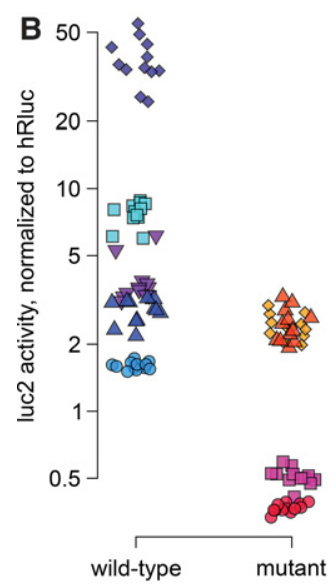

Figure 4. Tms $b 4 x$ titrates efficiently miR-1a/miR-206 in differentiated C2C12 cells. (A) Mutagenesis strategy. A luciferase reporter and G418 resistance cassette was introduced 286 bp downstream from the Tmsb4x poly(A) signal, and the Tmsb4x 3' UTR was replaced by a copy where the miR-1a/miR-206 seed match is either replaced by itself ("wt") or by a hexamer that is not matched by any known murine miRNA seed ("mutant"). $(B)$ Luciferase activity was assessed in each of the five wild-type and four mutant polyclonal cell lines after differentiation. Each cell line was analyzed as 12 technical replicates (replicates for the same cell line are represented by the same symbol and same color). Mixed-effect linear modeling (taking into account heteroscedasticity within each genotype) shows that genotype of the Tms $b 4 x$ miR-1a/miR-206 binding site has a significant effect on reporter activity $(p=0.0285)$.

Our measurements indicate that miR-1a/miR-206 and miR-133 intracellular concentrations range between 0.2 and $20 \mathrm{nM}$ in differentiating $\mathrm{C} 2 \mathrm{C} 12$ cells, while the total concentration of their differential RIP-seq-validated targets falls in the micromolar range. Our observation of Tms $4 x$-mediated titration is thus consistent with the conclusions of Bosson et al. (2014). It is, however, hard to reconcile with the notion proposed by Denzler et al. (2016), stating that an efficient titrating site has to reach $~ 10 \%-40 \%$ of the effective target abundance, which can be roughly estimated by the total concentration of 6-, 7-, and 8-mer 3' UTR sites for the miRNA of interest. In our libraries, the Tms $b 4 x$ miR-1a/miR-206 binding site accounts for $\sim 1 \%$ of the total miR-1a/miR-206 3' UTR sites.

Our results thus show that some mRNAs can modulate miRNA activity by titration. Such function could be selected in evolution if beneficial, explaining why some miRNA binding sites are conserved while they are located in genes that are not strongly repressed enough by the miRNAs to be functionally regulated. For example, Tms $b 4 x$ may not be repressed enough to be functionally sensitive to miR-1a/miR-206, and its miR-1a/miR-206 binding site could only be conserved because of its miR-1a/miR-206-titrating action: Tms $b 4 x$ would, therefore, be a false positive in current target identification procedures. 
A
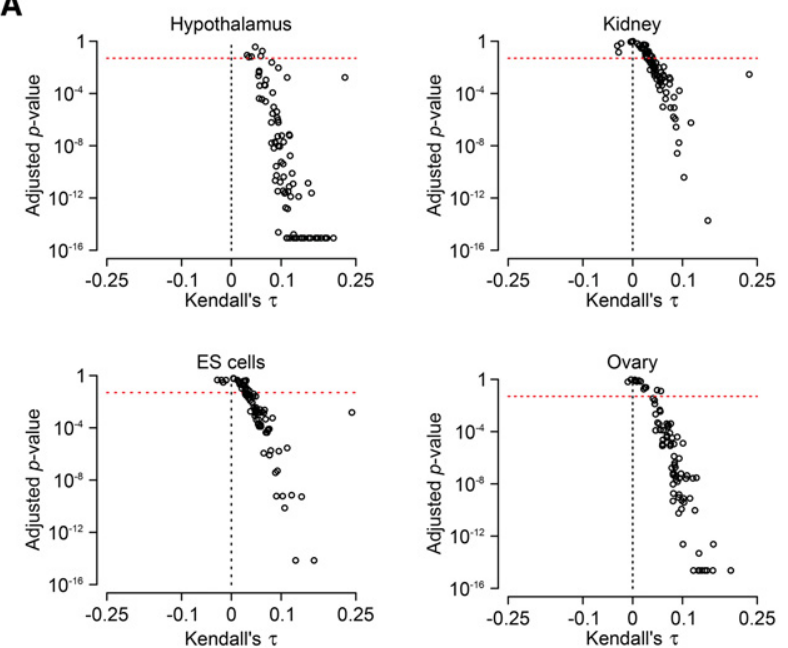

B
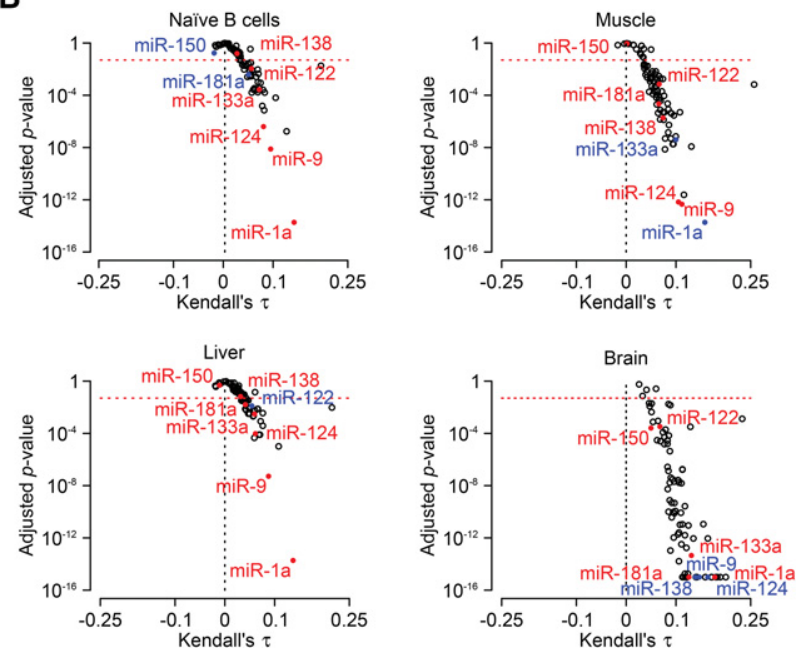

Figure 5. The most highly expressed genes tend to bear the most highly conserved miRNA binding sites. ( $A$ ) Volcano plots represent correlation coefficients between microarray signal and the aggregate probability of conserved targeting $\left(P_{C T}\right)$ for each mRNA ( $x$-axis), and their $p$-values ( $y$-axis). Each miRNA family is represented by a circle. $p$-values were adjusted using the Benjamini-Hochberg correction. The dotted red line indicates an adjusted $p$-value of 0.05 and the dotted black line indicates a correlation coefficient of zero. Adjusted $p$-values lower than $2.2 \times 10^{-16}$ were set to $2.2 \times$ $10^{-16}$ for graphical clarity. (B) Same conventions as in panel $A$, but miRNA families with highly specific expression patterns are colored (red: miRNA specific for another tissue than the one analyzed; blue: miRNA specific for the analyzed tissue).

\section{Titration refines miRNA expression patterns}

While half a dozen mRNAs appear to exert a clear effect on miRNA titration in differentiating C2C12 cells, these genes only constitute a minority of predicted miR-1a/miR-206 and miR-133 targets. It is possible that most predicted targets do not efficiently titrate miRNAs in any cell type. Alternatively, one can imagine that additional titrators exist for miR-1a/miR-206 and miR-133 in other cell types, where they are expressed abundantly enough.

A testable prediction can be implied from the latter possibility: If, indeed, some mRNAs play a beneficial miRNA titrating role in various cell types, then in each of these cell types, titrating
mRNAs should be highly expressed. The more beneficial the titration, the more conserved the interaction between these mRNAs and the miRNA: It can thus be expected that the most highly expressed miRNA targets should be under the strongest selective pressure to keep their miRNA binding sites. Hence, if mRNAs can exert an efficient titration of miRNAs, one would expect a positive correlation between mRNA abundance and the conservation of their miRNA binding sites in most tissues. Real targets are not expected to exhibit such a correlation, but as they are expected to be outnumbered by physiologically insensitive targets (the activity for most genes in animals being robust to an $\approx$ twofold change in expression), they should not affect the overall correlation.

For each gene, we thus compared miRNA binding site conservation (quantified by their $P_{C T}$ [Friedman et al. 2009]) to mRNA abundance in publicly available transcriptomic data sets from a variety of mouse tissues (see Supplemental Table S4). We observed that, for most murine miRNA families, mRNA abundance is, indeed, positively correlated with miRNA binding site conservation (positive Kendall's $\tau$ correlation coefficient, with a low adjusted $p$-value) (bottom right quadrants in the volcano plots shown in Fig. 5A and Supplemental Fig. S6; see also Farh et al. [2005]; Sun et al. [2012]). Note that the $P_{C T}$ compensates for $3^{\prime}$ UTR overall conservation (binding sites located in highly conserved UTRs have to be even more conserved themselves to attain the same $P_{C T}$ than binding sites in poorly conserved UTRs). This feature corrects potential biases in sequence conservation between poorly and abundantly expressed genes.

Interestingly, correlation was particularly strong not only for miRNAs that are highly expressed in the analyzed tissue, such as miR-1a/miR-206 and miR-133 in muscle, but also for miRNAs that are specific to a tissue other than the one analyzed (e.g., liver-specific miR-122 in the muscle) (see Fig. 5B). This suggests that the transcriptome of each cell type is not under a strong selective pressure to modulate its abundant miRNAs. It mostly titrates miRNAs specific for other tissues (presumably, whose expression is detrimental in that cell type). A notable exception to this rule is the brain, where neuron-specific miRNAs seem to exert the strongest selective pressure on miRNA binding sites in the transcriptome (see bottom right panel of Fig. 5B). This may be due to the large diversity among neurons, with miRNA titration being beneficial for some neuron-specific miRNAs in neurons that do not express them. Of note, miRNAs specific to another tissue than the one analyzed tend to be expressed at very low levels, casting doubt on the biological advantage of titrating miRNAs that are already hardly active. But mRNAs themselves could contribute to the decrease in miRNA levels through target-mediated degradation (Ameres et al. 2010; Xie et al. 2012; Denzler et al. 2016), in which case interaction with these miRNAs in these cell types could modulate miRNA efficiently, not through pure competition but by promoting miRNA degradation.

Our results suggest that various cell types express high levels of mRNAs that either titrate or promote the degradation of miRNAs which are most strongly expressed in other cell types. These considerations could promote a new interpretation of a well-known phenomenon: miRNAs and their predicted targets tend to be expressed in an overlapping, yet noncoincident fashion. Cells expressing highest miRNA levels tend to be devoid of target expression and reciprocally (Farh et al. 2005; Stark et al. 2005; Shkumatava et al. 2009). When miRNA expression varies continuously across the analyzed cell bins, miRNAs and their predicted targets mostly overlap in cells where both the miRNA and the

\section{Genome Research}

www.genome.org 
predicted targets are moderately expressed (Farh et al. 2005). It has been proposed that such organization implies that miRNAs preferentially repress targets in cells where their targets are already partially repressed by other mechanisms. Alternatively, we propose that some mRNAs titrate miRNAs preferentially in cells where the miRNA is already poorly expressed.

\section{False positives in comparative genomics}

Computational prediction of miRNA targets usually relies on the identification of phylogenetically conserved seed matches (Friedman and Burge 2014). Our results suggest that just a small fraction of genes with conserved seed matches are sensitive enough to small changes in expression to be functionally regulated by miRNAs (Figs. 1, 2). Among the remaining predicted targets, some may bear conserved seed matches because of their miRNA-titrating activity (Figs. 3-5). It is hard to tell how many titrator mRNAs exist: For every gene, even among those that appear to be poorly expressed, it is formally possible that its expression level is high in a particular cell type or developmental stage, where it could exert a beneficial miRNA titration. Alternatively, it is possible that many predicted targets are neither functionally sensitive to miRNA-guided repression, nor efficient at titrating miRNAs. Genes in this "gray zone" would thus exhibit conserved seed matches for a reason not attributable to functional targeting nor to efficient miRNA titration. Phylogenetic conservation of such seed matches would remain to be explained. We thus decided to explore the possibility that the results of some comparative genomics-based methods could be contaminated by false positives.

It is indeed possible that a sequence may be conserved because of some other, miRNA-independent reason, while fortuitously being complementary to a miRNA seed (Friedman et al. 2009). Conservation of that sequence would thus be mistakenly attributed to the functionality of the miRNA/mRNA interaction. It is possible to calculate an estimation of the frequency of such false positives by scoring conserved seed matches in species devoid of miRNAs with that seed sequence (miRNAs sharing the same seed belong to the same "miRNA family"). Using the human-centered 100-species whole genome alignment from UCSC (Rosenbloom et al. 2015), we identified $3^{\prime}$ UTR seed matches that appear to be more conserved than the miRNA seed itself (see Fig. 6A for an example). Such "overconserved" seed matches could result in false positives in miRNA target prediction schemes. Their conservation is independent of their interaction with the miRNA: It may be due to other trans factors (such as DNA-binding proteins or RNA-binding proteins), for example.

Comparative genomics-based target prediction programs screen conserved miRNA binding sites for additional criteria (local AU content, pairing to the miRNA 3' moiety, etc.), which may decrease the false positive rate. Indeed, binding sites predicted by the most popular target prediction algorithms tend to be less frequently overconserved than the bulk of $3^{\prime}$ UTR seed matches (cf. Fig. 6B,C; see Supplemental Table S5; note that a widely used prediction program, TargetScan, cannot be analyzed here: it does not rely on phylogenetic conservation for miRNAs specific to mammals or to shallower mammalian clades). This observation indicates that they are less prone to selecting overconserved seed matches than a simple seed match search. Yet, even these programs are heavily contaminated with overconserved seed matches (e.g., $\approx 50 \%-70 \%$ for most Hominidae-specific seeds in microT and miRanda predictions).
Frequency of overconserved sites shows a striking dependency on the phylogenetic depth of the clade of interest: Shallow clades (e.g., Hominidae) tend to exhibit higher rates of overconserved sites than deep clades (e.g., Euteleostomi). We could imagine several interpretations for that phenomenon: (1) miRNA annotation could be less reliable for poorly conserved miRNAs, resulting in a high contamination of Hominidae-specific miRNAs by small RNAs which are actually not miRNAs; (2) any given seed match is less likely to be conserved outside deep clades than outside shallow clades, because it has a higher chance of being lost in a longer evolutionary divergence; or (3) there are more species outside shallow clades than outside deep clades, increasing the chances that an outer species possesses the seed match. In order to assess these possibilities, we measured the proportion of seed matches conserved outside four clades of various depths and for variably conserved seeds (see Fig. 6D; Supplemental Fig. S7). The results show that the number of conserved seed matches decreases when assessing conservation outside deeper clades, and the decrease is similar for all four seed types (Hominidae-specific, Catarrhini-specific, Boreoeutheria-specific, and Euteleostomi-specific seeds). This observation indicates that such decrease is not due to a differential quality of miRNA annotation between deeply conserved and poorly conserved miRNAs. It is simply a consequence of the arborescent structure of evolution (interpretations [2] and [3] above). In fact, hexamers that do not match the seed of any known vertebrate miRNA exhibit the same pattern (in black in Fig. 6D), confirming that it is due to the tendency for sequence elements to be more easily conserved outside shallow clades than outside deep clades.

Hence, the false positive rate for miRNA seeds in general is likely to be closer to the rate of overconserved sites for Hominidae-specific seeds than for Euteleostomi-specific seeds: Euteleostomispecific seeds have lower rates of overconserved sites only because of the general property of overconserved sites to be rare in deep clades. But the propensity of the analyzed target prediction programs to capture false positives is probably similar to that of Hominidae-specific miRNAs, because they use the same predicting criteria for deeply conserved and poorly conserved miRNA families, and they are likely to be similarly contaminated by transcription factor or RNA-binding protein binding sites. Thus, by this measure, the false positive rate for microT and miRanda appears to approach $50 \%$ or $70 \%$, while our approach is unable to estimate it for PicTar and TargetScan, which do not attempt to predict biological relevance by phylogenetic analysis for the least conserved miRNAs.

\section{Discussion}

Assessment of the involvement of miRNAs in a biological process usually relies on two types of tests: measurement of the effect of a miRNA on the expression of a target gene by molecular biology methods (e.g., reporter assays), and the identification of phylogenetically conserved miRNA binding sites in the target mRNA. Techniques in molecular biology may reveal a direct or indirect effect of the miRNA on a gene's expression, but they cannot address the physiological significance of such regulation. Hence, the demonstration of phylogenetic conservation of the interaction between a miRNA and a mRNA has been central in the validation of proposed interactions: Even if the target is poorly repressed, its regulation was considered biologically important because it is conserved in evolution.

Lists of miRNA targets found by molecular biology experiments or by computational predictions are frequently used to infer 
A
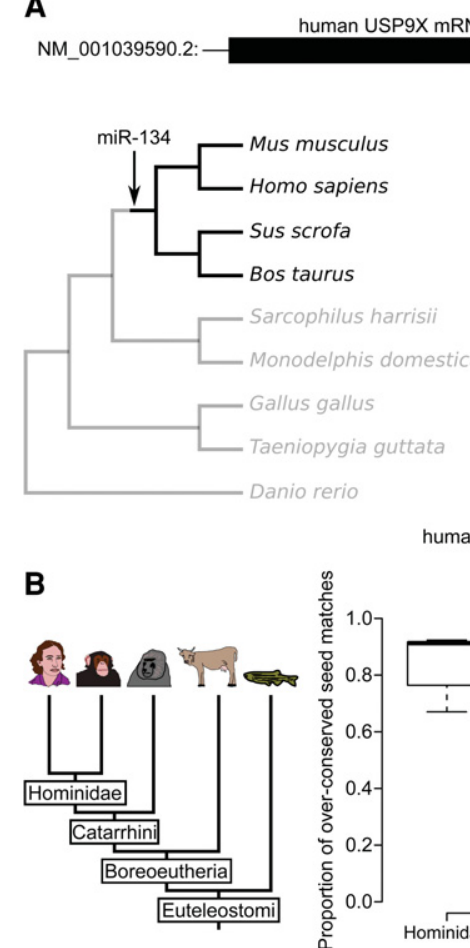

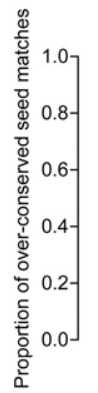

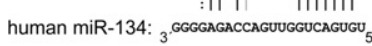

B

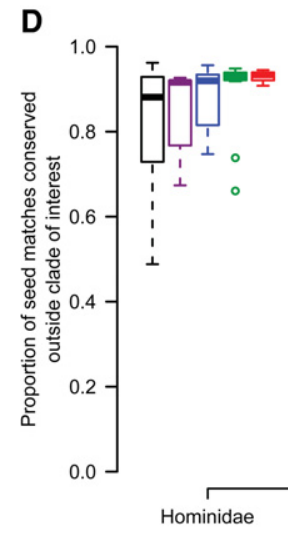

3. UTR seed matches:

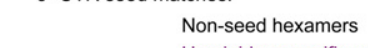

Hominidae-specific seeds

Catarrhini-specific seeds

Boreoeutheria-specific seeds

Euteleostomi-specific seeds

$\bigsqcup_{\perp} \quad \begin{gathered}T \\ \quad\end{gathered}$

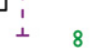

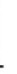

8

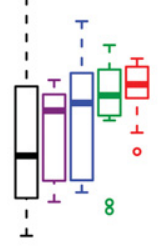

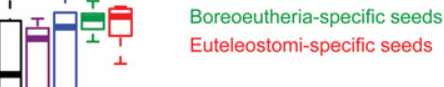

C

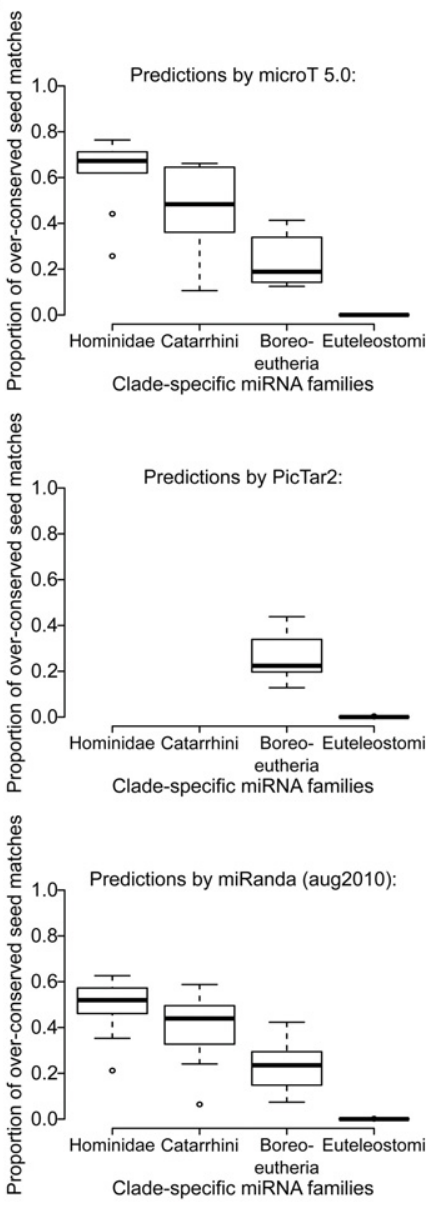

Figure 6. Computationally identified conserved seed matches are frequently more conserved than miRNA seeds themselves. (A) The miR-134 family is specific to placental mammals, but its predicted binding site in USP9X is more broadly conserved. (B) Four vertebrate clades had enough clade-specific miRNA families for a detailed statistical analysis (10 Hominidae-specific families, 14 Catarrhini-specific families, 14 Boreoeutheria-specific families, 10 Euteolostomi-specific families) (see Supplemental Fig. S7). Each point in the boxplot represents an miRNA seed family. The proportion of overconserved $3^{\prime}$ UTR seed matches is defined as the fraction of matches that are conserved in at least one species outside the clade of interest. (C) Proportion of overconserved seed matches among the predictions of several miRNA target prediction programs. Note that PicTar2 ignores Hominidae- and Catarrhini-specific miRNAs, while TargetScan predicts and ranks targets of mammalian-specific miRNAs without using phylogenetic conservation. In order to make every program output comparable, analyses were restricted to perfect seed matches in $3^{\prime}$ UTRs, excluding matches that overlap exon-exon junctions (see Supplemental Table S5 for detailed statistics). (D) 3' UTR seed matches were analyzed as in panel B, but each group of clade-specific seeds was scored for conserved seed matches outside each of the four clades. Nonseed hexamers (i.e., hexamers that do not constitute the seed of any vertebrate miRNA in miRBase 21) were analyzed identically.

miRNA biological functions: Depending on prediction programs, false positive rates of several tens of percent thus heavily contaminate such functional inferences. miRNAs certainly have a real physiological effect but only through regulation of genes whose activity is sensitive to moderate repression. It has been proposed that miRNAs act globally on gene networks and the simultaneous modest regulation of many genes would trigger a large phenotypic response (Flynt and Lai 2008). In theory, this property could explain why individual miRNA/mRNA interactions do not control any selectable phenotype, while the coordinated regulation of many mRNAs does. However, it should be kept in mind that each individual miRNA binding site evolves independently from

\section{Genome Research}

www.genome.org 
the others: If it does not have a selectable effect by itself, then it should mutate at the same rate as nonfunctional genomic elements. And indeed, genetic validation of the physiological role of mRNA/miRNA interactions usually points to a single target being responsible for all the reported phenotypes of any miRNA mutant. To our knowledge, there is currently only one in vivo experiment showing that multiple targets contribute to a miRNA mutant phenotype: the string and wingless targets for miR-965 in Drosophila (Verma and Cohen 2015). All the other published in vivo assessments of the implication of targets in miRNA mutant phenotypes pointed to a single target each.

Recent technological advances now allow a precise dissection of regulatory networks: Mutating miRNAs and targets of interest with the CRISPR/Cas9 system, it is now possible to disrupt and restore individual interactions on demand (Ecsedi et al. 2015). It is expected that similar analyses will be performed in the near future: Our prediction is that they will show that the observed phenotypes of miRNA mutants are due to a few dose-sensitive genes, rather than to a global misregulation of the whole "target-ome."

That notion could explain why miRNA mutants usually exhibit much more specific and limited phenotypes than could be anticipated from the functions of their numerous published targets (Alvarez-Saavedra and Horvitz 2010; Park et al. 2010; Chen et al. 2014; Ecsedi et al. 2015) and why phenotypes of miRNA mutants are often hard to infer a priori from the list of expected targets (Li and Carthew 2005; Sokol et al. 2008; Elia et al. 2009; Shaw et al. 2010). Our results thus imply that microRNA target predictions should be used with caution, always considering the possibility that any given predicted target is a false positive.

\section{Methods}

\section{Measurement of inter-individual variability in neutrophil} gene expression

Pathogen-free S/SPF C57BL/6J mice were obtained from Charles River Laboratories. Experiments were performed using 103 month-old male mice. Approval for these studies was obtained from the Ethics Committee on Animal Research of the Languedoc-Roussillon region (CE-LR-0505). Five blood samples were analyzed separately ("biological replicates"), and five others were pooled, then split into five "technical replicates." All 10 samples were then treated identically in a double-blind manner. mRNAs were quantified using Affymetrix whole-genome array HT MG-430 PM and the 3'-IVT labeling kit, by the IRB microarray facility (IRB, CHRU-INSERM-UM1 Montpellier). Additional experimental details can be found in Supplemental Experimental Procedures, section 1.1.

\section{RIP-seq-based identification of miRNA targets}

C2C12 differentiation was induced as described (Sweetman et al. 2008). Two days later, cells were transfected with $20 \mathrm{nM}$ antisense oligonucleotides using Lipofectamine 2000 (Invitrogen). Oligonucleotides are described in Supplemental Experimental Procedures, section 1.6. Cells were cross-linked $24 \mathrm{~h}$ after transfection. For AGO RIP-seq, cDNA libraries were prepared from immunoprecipitated RNA by BGI Tech Solutions using poly(A)independent RNA-seq, with the fragmentation step performed prior to reverse-transcription. Additional experimental details can be found in Supplemental Experimental Procedures, section 1.3.1.

\section{Calculation of mRNA-mediated miRNA titration efficiency}

Cell volumes were calculated by approximating cells to ellipsoids, whose semimajor axis and semiminor axis were measured on microscopy pictures of trypsinized cells, resuspended in medium. Pictures were internally calibrated using $4.5-\mu \mathrm{m}$ diameter beads, and cells were colored with Texas red-conjugated wheat germ agglutinin for a better contrast.

The equilibrium between free and bound miRNA was calculated using the dissociation constant measured by Wee et al. (2012):

$$
\frac{[\text { free miRNA }][\text { free binding sites }]}{[\text { miRNA/mRNA duplex }]}=K d
$$

with:

- $[$ miRNA/mRNA duplex $]=$ the total concentration of miRNA/ mRNA duplex between the miRNA of interest and its mRNA targets,

- measured miRNA concentration $=[$ free $m i R N A]+[$ miRNA/mRNA duplex], and

- measured binding site concentration $=[$ free binding site $]+[$ miRNA/ $m R N A$ duplex].

"Measured binding site concentration" was measured by summing the concentrations of every experimentally identified target, weighted by their number of perfect or imperfect seed matches (considering the three most frequently observed imperfect seed matches) (see their sequences in the legend for Fig. 3D). Conceptual loss of an individual binding site was achieved by decreasing that weight by one site.

\section{Comparison of seed match conservation with seed conservation in vertebrates}

Orthologous sites in 3' UTRs were extracted from UCSC Genome Browser's 100 species whole-genome alignment using reference gene UTR annotation. Clade-specific miRNA seeds were defined as the seeds present in at least $75 \%$ of the species in the clade of interest, while being absent in every species outside that clade. For a seed to be flagged as "absent" from a species, it had to be absent from the set of miRBase-annotated miRNA seeds for that species, but also that species' genome was required to be devoid of any predicted hairpin orthologous to known hairpins expressing a miRNA with that seed in other vertebrate species. Additional experimental details can be found in Supplemental Experimental Procedures, section 1.5 .

\section{Data access}

Raw and processed microarray data from this study have been submitted to the NCBI Gene Expression Omnibus (GEO; http://www. ncbi.nlm.nih.gov/geo/) under accession number GSE59549. Raw RNA-seq data have been submitted to the NCBI Sequence Read Archive (SRA; http://www.ncbi.nlm.nih.gov/sra/) under accession numbers SRP036149 (RNA-seq during C2C12 differentiation) and SRP065380 (RIP-seq on differentiation day 3).

\section{Acknowledgments}

We thank Prof. Z. Mourelatos for the generous gift of anti-mammalian Ago 2A8 ascites, as well as Y. Tomari, S. Chambeyron, J. Martinez, I. Busseau, and G. Canal for critical reading of the manuscript, and M. Baragatti for assistance with statistical analyses. Affymetrix microarrays were processed in the Microarray core facility of the IRB, CHRU-INSERM-UM1 
Montpellier. Cytometry was performed at the Montpellier RIO imaging facility. Research in the Seitz lab is funded by the Human Frontier Science Program (CDA-00017/2010-C), CNRS, and Sanofi (ATIP-Avenir program), and La Ligue nationale contre le cancer (postdoctoral fellowship to N.P.). We thank a community leader who suggested important modifications, which were made in the proof stage.

Author contributions: N.P., J.P., F.A., and H.S. conceived the experiments. N.P., L.M., A.S., and J.P. performed the experiments. N.P., B.L., and H.S. analyzed the data. N.P., B.L., and H.S. wrote the article.

\section{References}

Agarwal V, Bell GW, Nam JW, Bartel DP. 2015. Predicting effective microRNA target sites in mammalian mRNAs. eLife 4: e05005.

Alvarez-Saavedra E, Horvitz HR. 2010. Many families of C. elegans microRNAs are not essential for development or viability. Curr Biol 20: 367-373.

Ameres SL, Horwich MD, Hung JH, Xu J, Ghildiyal M, Weng Z, Zamore PD. 2010. Target RNA-directed trimming and tailing of small silencing RNAs. Science 328: 1534-1539.

Baek D, Villén J, Shin C, Camargo FD, Gygi SP, Bartel DP. 2008. The impact of microRNAs on protein output. Nature 455: 64-71.

Bartel DP. 2009. MicroRNAs: target recognition and regulatory functions. Cell 136: 215-233.

Bartel DP, Chen CZ. 2004. Micromanagers of gene expression: the potentially widespread influence of metazoan microRNAs. Nat Rev Genet 5: 396-400.

Bauernfeind F, Rieger A, Schildberg FA, Knolle PA, Schmid-Burgk JL, Hornung V. 2012. NLRP3 inflammasome activity is negatively controlled by miR-223. J Immunol 189: 4175-4181.

Bazzini AA, Lee MT, Giraldez AJ. 2012. Ribosome profiling shows that miR430 reduces translation before causing mRNA decay in zebrafish. Science 336: $233-237$

Betel D, Koppal A, Agius P, Sander C, Leslie C. 2010. Comprehensive modeling of microRNA targets predicts functional non-conserved and noncanonical sites. Genome Biol 11: R90.

Bosson AD, Zamudio JR, Sharp PA. 2014. Endogenous miRNA and target concentrations determine susceptibility to potential ceRNA competition. Mol Cell 56: 347-359.

Chen CZ, Li L, Lodish HF, Bartel DP. 2004. MicroRNAs modulate hematopoietic lineage differentiation. Science 303: 83-86.

Chen JF, Mandel EM, Thomson JM, Wu Q, Callis TE, Hammond SM, Conlon FL, Wang DZ. 2006. The role of microRNA-1 and microRNA133 in skeletal muscle proliferation and differentiation. Nat Genet 38: 228-233.

Chen YW, Song S, Weng R, Verma P, Kugler JM, Buescher M, Rouam S, Cohen SM. 2014. Systematic study of Drosophila microRNA functions using a collection of targeted knockout mutations. Dev Cell 31: 784-800.

Cheung VG, Conlin LK, Weber TM, Arcaro M, Jen KY, Morley M, Spielman RS. 2003. Natural variation in human gene expression assessed in lymphoblastoid cells. Nat Genet 33: 422-425.

Dang VT, Kassahn KS, Marcos AE, Ragan MA. 2008. Identification of human haploinsufficient genes and their genomic proximity to segmental duplications. Eur J Hum Genet 16: 1350-1357.

Denzler R, Agarwal V, Stefano J, Bartel DP, Stoffel M. 2014. Assessing the ceRNA hypothesis with quantitative measurements of miRNA and target abundance. Mol Cell 54: 766-776.

Denzler R, McGeary SE, Title AC, Agarwal V, Bartel DP, Stoffel M. 2016 Impact of microRNA levels, target-site complementarity, and cooperativity on competing endogenous RNA-regulated gene expression. Mol Cell 64: 565-579.

Ebert MS, Sharp PA. 2010. Emerging roles for natural microRNA sponges. Curr Biol 20: R858-R861.

Ecsedi M, Rausch M, Großhans H. 2015. The let-7 microRNA directs vulval development through a single target. Dev Cell 32: 335-344.

Elia L, Quintavalle M, Zhang J, Contu R, Cossu L, Latronico MV, Peterson KL, Indolfi C, Catalucci D, Chen J, et al. 2009. The knockout of miR143 and -145 alters smooth muscle cell maintenance and vascular homeostasis in mice: correlates with human disease. Cell Death Differ 16: 1590-1598.

Farh KK, Grimson A, Jan C, Lewis BP, Johnston WK, Lim LP, Burge CB, Bartel DP. 2005. The widespread impact of mammalian microRNAs on mRNA repression and evolution. Science 310: 1817-1821.
Flynt AS, Lai EC. 2008. Biological principles of microRNA-mediated regulation: shared themes amid diversity. Nat Rev Genet 9: 831-842.

Friedman RC, Burge CB. 2014. MicroRNA target finding by comparative genomics. Methods Mol Biol 1097: 457-476.

Friedman RC, Farh KK, Burge CB, Bartel DP. 2009. Most mammalian mRNAs are conserved targets of microRNAs. Genome Res 19: 92-105.

Garcia DM, Baek D, Shin C, Bell GW, Grimson A, Bartel DP. 2011. Weak seed-pairing stability and high target-site abundance decrease the proficiency of lsy-6 and other microRNAs. Nat Struct Mol Biol 18: 1139-1146.

Goljanek-Whysall $\mathrm{K}$, Pais $\mathrm{H}$, Rathjen $\mathrm{T}$, Sweetman $\mathrm{D}$, Dalmay $\mathrm{T}$, Münsterberg A. 2012. Regulation of multiple target genes by miR-1 and miR-206 is pivotal for C2C12 myoblast differentiation. J Cell Sci 125: 3590-3600.

Guo H, Ingolia NT, Weissman JS, Bartel DP. 2010. Mammalian microRNAs predominantly act to decrease target mRNA levels. Nature 466: 835-840.

Haneklaus M, Gerlic M, Kurowska-Stolarska M, Rainey AA, Pich D, McInnes IB, Hammerschmidt W, O'Neill LA, Masters SL. 2012. Cutting edge: miR-223 and EBV miR-BART15 regulate the NLRP3 inflammasome and IL-1 $\beta$ production. J Immunol 189: 3795-3799.

Hata A, Lieberman J. 2015. Dysregulation of microRNA biogenesis and gene silencing in cancer. Sci Signal 8: re3.

Hendrickson DG, Hogan DJ, McCullough HL, Myers JW, Herschlag D, Ferrell JE, Brown PO. 2009. Concordant regulation of translation and mRNA abundance for hundreds of targets of a human microRNA. PLoS Biol 7: e1000238.

Huang N, Lee I, Marcotte EM, Hurles ME. 2010. Characterising and predicting haploinsufficiency in the human genome. PLoS Genet 6: e1001154

Hutvágner G, Simard MJ, Mello CC, Zamore PD. 2004. Sequence-specific inhibition of small RNA function. PLoS Biol 2: E98.

Iwakawa HO, Tomari Y. 2015. The functions of microRNAs: mRNA decay and translational repression. Trends Cell Biol 25: 651-665.

Johnnidis JB, Harris MH, Wheeler RT, Stehling-Sun S, Lam MH, Kirak O, Brummelkamp TR, Fleming MD, Camargo FD. 2008. Regulation of progenitor cell proliferation and granulocyte function by microRNA-223. Nature 451: 1125-1129.

Kim HK, Lee YS, Sivaprasad U, Malhotra A, Dutta A. 2006. Muscle-specific microRNA miR-206 promotes muscle differentiation. J Cell Biol 174 677-687.

Kleinstiver BP, Pattanayak V, Prew MS, Tsai SQ, Nguyen NT, Zheng Z, Joung JK. 2016. High-fidelity CRISPR-Cas9 nucleases with no detectable genome-wide off-target effects. Nature 529: 490-495.

Kozomara A, Griffiths-Jones S. 2014. miRBase: annotating high confidence microRNAs using deep sequencing data. Nucleic Acids Res 42: D68-D73.

Krek A, Grün D, Poy MN, Wolf R, Rosenberg L, Epstein EJ, MacMenamin P, da Piedade I, Gunsalus KC, Stoffel M, et al. 2005. Combinatorial microRNA target predictions. Nat Genet 37: 495-500.

Lai EC. 2002. MicroRNAs are complementary to 3' UTR sequence motifs that mediate negative post-transcriptional regulation. Nat Genet 30: 363-364.

Laurie-Ahlberg CC, Wilton AN, Curtsinger JW, Emigh TH. 1982. Naturally occurring enzyme activity variation in Drosophila melanogaster. I. Sources of variation for 23 enzymes. Genetics 102: 191-206.

Leung AK, Young AG, Bhutkar A, Zheng GX, Bosson AD, Nielsen CB, Sharp PA. 2011. Genome-wide identification of Ago2 binding sites from mouse embryonic stem cells with and without mature microRNAs. Nat Struct Mol Biol 18: 237-244.

Lewis BP, Shih IH, Jones-Rhoades MW, Bartel DP, Burge CB. 2003. Prediction of mammalian microRNA targets. Cell 115: 787-798.

Lewis BP, Burge CB, Bartel DP. 2005. Conserved seed pairing, often flanked by adenosines, indicates that thousands of human genes are microRNA targets. Cell 120: $15-20$.

Li X, Carthew RW. 2005. A microRNA mediates EGF receptor signaling and promotes photoreceptor differentiation in the Drosophila eye. Cell 123: 1267-1277.

Loeb GB, Khan AA, Canner D, Hiatt JB, Shendure J, Darnell RB, Leslie CS, Rudensky AY. 2012. Transcriptome-wide miR-155 binding map reveals widespread noncanonical microRNA targeting. Mol Cell 48: 760-770.

Paraskevopoulou MD, Georgakilas G, Kostoulas N, Vlachos IS, Vergoulis T, Reczko M, Filippidis C, Dalamagas T, Hatzigeorgiou AG. 2013. DIANAmicroT web server v5.0: service integration into miRNA functional analysis workflows. Nucleic Acids Res 41(Web Server issue): W169-W173.

Park CY, Choi YS, McManus MT. 2010. Analysis of microRNA knockouts in mice. Hum Mol Genet 19(R2): R169-R175.

Poliseno L, Salmena L, Zhang J, Carver B, Haveman WJ, Pandolfi PP. 2010. A coding-independent function of gene and pseudogene mRNAs regulates tumour biology. Nature 465: 1033-1038.

Rockman MV, Wray GA. 2002. Abundant raw material for cis-regulatory evolution in humans. Mol Biol Evol 19: 1991-2004.

Rosenbloom KR, Armstrong J, Barber GP, Casper J, Clawson H, Diekhans M, Dreszer TR, Fujita PA, Guruvadoo L, Haeussler M, et al. 2015. The UCSC

\section{Genome Research}

www.genome.org 
Genome Browser database: 2015 update. Nucleic Acids Res 43: D670-D681.

Salmena L, Poliseno L, Tay Y, Kats L, Pandolfi PP. 2011. A ceRNA hypothesis: the Rosetta Stone of a hidden RNA language? Cell 146: 353-358.

Seitz H. 2009. Redefining microRNA targets. Curr Biol 19: 870-873.

Selbach M, Schwanhäusser B, Thierfelder N, Fang Z, Khanin R, Rajewsky N. 2008. Widespread changes in protein synthesis induced by microRNAs. Nature 455: 58-63.

Shaw WR, Armisen J, Lehrbach NJ, Miska EA. 2010. The conserved miR-51 microRNA family is redundantly required for embryonic development and pharynx attachment in Caenorhabditis elegans. Genetics 185: 897-905.

Shenoy A, Blelloch RH. 2014. Regulation of microRNA function in somatic stem cell proliferation and differentiation. Nat Rev Mol Cell Biol 15: $565-576$.

Shkumatava A, Stark A, Sive H, Bartel DP. 2009. Coherent but overlapping expression of microRNAs and their targets during vertebrate development. Genes Dev 23: 466-481.

Sokol NS, Xu P, Jan YN, Ambros V. 2008. Drosophila let-7 microRNA is required for remodeling of the neuromusculature during metamorphosis. Genes Dev 22: 1591-1596.

Stark A, Brennecke J, Bushati N, Russell RB, Cohen SM. 2005. Animal microRNAs confer robustness to gene expression and have a significant impact on 3' UTR evolution. Cell 123: 1133-1146.

Subkhankulova T, Gilchrist MJ, Livesey FJ. 2008. Modelling and measuring single cell RNA expression levels find considerable transcriptional differences among phenotypically identical cells. BMC Genomics 9: 268.
Sun K, Westholm JO, Tsurudome K, Hagen JW, Lu Y, Kohwi M, Betel D, Gao FB, Haghighi AP, Doe CQ, et al. 2012. Neurophysiological defects and neuronal gene deregulation in Drosophila mir-124 mutants. PLoS Genet 8: e1002515.

Sweetman D, Goljanek K, Rathjen T, Oustanina S, Braun T, Dalmay T, Münsterberg A. 2008. Specific requirements of MRFs for the expression of muscle specific microRNAs, miR-1, miR-206 and miR-133. Dev Biol 321: 491-499.

Verma P, Cohen SM. 2015. miR-965 controls cell proliferation and migration during tissue morphogenesis in the Drosophila abdomen. eLife $\mathbf{4}$ doi: 10.7554/eLife.07389.

Vlachos IS, Paraskevopoulou MD, Karagkouni D, Georgakilas G, Vergoulis T, Kanellos I, Anastasopoulos IL, Maniou S, Karathanou K, Kalfakakou D, et al. 2015. DIANA-TarBase v7.0: indexing more than half a million experimentally supported miRNA:mRNA interactions. Nucleic Acids Res 43 (Database issue): 153-159.

Wee LM, Flores-Jasso CF, Salomon WE, Zamore PD. 2012. Argonaute divides its RNA guide into domains with distinct functions and RNA-binding properties. Cell 151: 1055-1067.

Xie J, Ameres SL, Friedline R, Hung JH, Zhang Y, Xie Q, Zhong L, Su Q, He R, $\mathrm{Li} \mathrm{M}$, et al. 2012. Long-term, efficient inhibition of microRNA function in mice using rAAV vectors. Nat Methods 9: 403-409.

Received February 4, 2016; accepted in revised form October 6, 2016. 


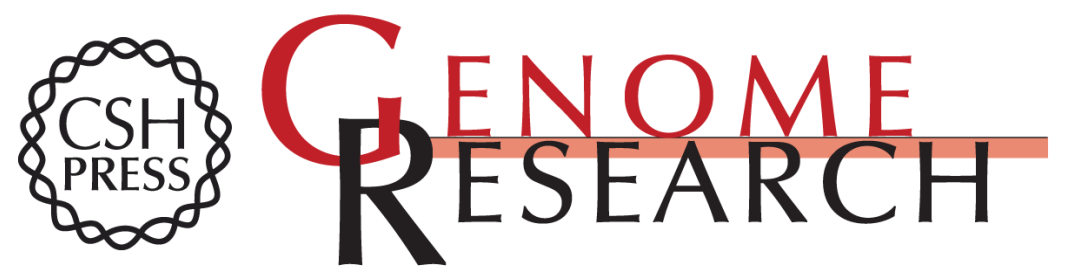

\section{microRNA target prediction programs predict many false positives}

Natalia Pinzón, Blaise Li, Laura Martinez, et al.

Genome Res. 2017 27: 234-245 originally published online November 15, 2016

Access the most recent version at doi:10.1101/gr.205146.116

\section{Supplemental http://genome.cshlp.org/content/suppl/2016/11/07/gr.205146.116.DC1 \\ Material http://genome.cshlp.org/content/suppl/2017/02/01/gr.205146.116.DC2}

References This article cites 65 articles, 14 of which can be accessed free at:

http://genome.cshlp.org/content/27/2/234.full.html\#ref-list-1

Creative This article is distributed exclusively by Cold Spring Harbor Laboratory Press for the Commons first six months after the full-issue publication date (see

License http://genome.cshlp.org/site/misc/terms.xhtml). After six months, it is available under a Creative Commons License (Attribution-NonCommercial 4.0 International), as described at http://creativecommons.org/licenses/by-nc/4.0/.

Email Alerting Receive free email alerts when new articles cite this article - sign up in the box at the Service top right corner of the article or click here.

\section{Affordable, Accurate Sequencing.}

To subscribe to Genome Research go to:

https://genome.cshlp.org/subscriptions 